（色材，58［4]200-203. 1985）

\title{
粉体の基礎物性に関する研究（第 $\mathbf{V}$ 報） \\ 貫入棒の粉体層への貫入特性および流出比と かさ密度・安息角との関係
}

\section{1. 緒言}

粉体の基礎物性を対象とした研究例 ${ }^{1,2)}$ の中, 著者らは 以前，1）容器に疎充てんした粉体層へ種々の高さから 円筒状の錘を，層の表面に底面を接触させ，垂直に置い た貫入丸棒 (木製) 上に自由落下させた場 合の貫入特 性 $^{3)}$ ，および 2) 円筒容器内に疎充てんした粉体層高を 変化させたとき, 底部オリフィスから流出する粉体の単 位時間あたりの流出量と流出速度との比 $\mathrm{K}$ (すなわち流 出比)について, これと粒径 $d$, 川北の式に打るタッ ピング定数 a (圧縮に関する定数)・1/b（付着力に関す る定数）および流動度 $\psi$ との各関係 ${ }^{4}$ を考察した。

本報では，貫入特性に関し粒子と棒の接触面の錘の重 量による摩擦の影響をみるため，a）貫入棒の側面にエ メリーペーパを貼付した場合と，さらにb）底面にも 貼付した場合について実験した。結果は貼付しない場合 と比較検討すると共に, $\mathrm{K}$ と静かさ密度 $\rho_{b_{1}}$ ・動かさ密 度 $\rho_{b 2}$ おょび安息角 $\theta$ との関係を調べた。

\section{2. 実験装置・試料}

図-1（a）の貫入度測定装置, 流出実験 装 置（図-1 (b)）扣よびかさ密度と安息角測定器（パウダテスタ, 細川ミクロン $\mathrm{KK}$ 製)をそれぞれ用いた。

供試試料を表-1 に示す。貫入度の測定はガラスビー ズ（粒径 $d: 0.180 \mathrm{~mm}, 2.030 \mathrm{~mm}$ ) を，流出実験には 全試料 (いずれも十分乾燥し, ‘ろるい’゙分級したもの) を用いた。

昭和 59.8.27 受理

* 足利工業大学経営工学科

足利市大前町 268-1 (T326)
湯 浅 泰 伸* . 山 城 光 雄*

\section{3. 実 験 方 法}

貫入実験は, 直径 $55 \mathrm{~mm}$, 高さ $150 \mathrm{~mm}$, 重さ $180 \mathrm{~g}$ の 貫入棒の側面にエメリーペーパ AA 60 を貼付した場合 と,さらに側面と底面に貼付した場合について行った。 実験では容器 ( $\phi 195 \mathrm{~mm}$, 高さ $200 \mathrm{~mm}$ の円筒容器) に 疎充てんしたガラスビーズ $(d: 0.180,2.030 \mathrm{~mm})$ の表 面上に，鉛直に貫入棒をのせて，一定の高さ $H: 50 \mathrm{~cm}$ から各重量をもつ円筒状の錘 $M(\mathrm{~g})$ を自由落下させた 場合に打㤋粉層内への棒の貫入深さ $x(\mathrm{~mm})$ を 3 回ずつ測定し，その平均值を用いた。な拉，貫入棒は容 器のほぼ中心の位置に括き，1回ごとに充てんし直して から貫入深さを測定した。

また，流出実験では $K(\mathrm{~g} / \mathrm{cm})$ と川北式かさ密度測定 器 IH-1000 (セイシン企業 KK 製) により測定した静 および動かさ密度 $\rho_{b 1}\left(\mathrm{~g} / \mathrm{cm}^{3}\right), \rho_{b 2}\left(\mathrm{~g} / \mathrm{cm}^{3}\right)$ および頭 を切った円錐ロート（上面抢よび底面の直径 $120 \mathrm{~mm}$, $13.5 \mathrm{~mm}$, 高さ $86 \mathrm{~mm}$, 頂角 $60^{\circ}$ ) の下 $10 \mathrm{~cm}$ のとこ ろにパウダテスタの安息角測定台を拈き, 分度器を使用 して各粉体の安息角 $\theta\left(^{\circ}\right)$ を測定した。

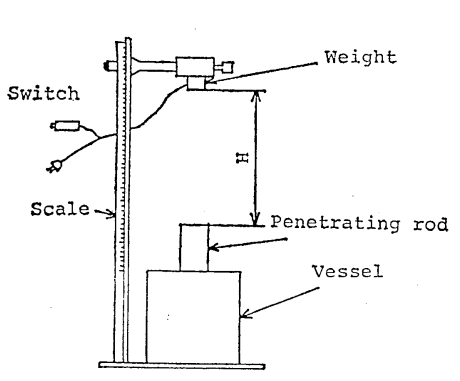

(a)

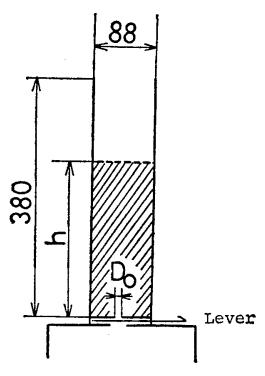

(b)
Fig. 1. Experimental apparatus 
Table 1. Sample properties

\begin{tabular}{l|c|c|c}
\hline \multicolumn{1}{c|}{ Sample } & Mean particle diameter $\mathrm{d}(\mathrm{mm})$ & Specific density \\
\hline Glass beads & $0.180, \quad 0.505, \quad 1.015, \quad 2.030$ & 2.23 \\
\hline Styrol resin & $0.359, \quad 0.505, \quad 2.605$, & 1.015 \\
\hline Silica sand & $0.180,0.254,0.505, \quad 0.715$ & 2.58 \\
\hline Carborundum & $0.180, \quad 0.505, \quad 1.435$, & 3.17 \\
\hline Silica gel & $0.505, \quad 0.715, \quad 1.015$, & 2.25 \\
\hline
\end{tabular}

Table 2. Summary of experimental values

\begin{tabular}{|c|c|c|c|c|c|}
\hline \multirow[t]{2}{*}{ Sample } & \multirow[t]{2}{*}{ Particle diameter $\mathrm{d}(\mathrm{mm})$} & \multirow{2}{*}{$\mathrm{K}(=\mathrm{W} / \mathrm{v})(\mathrm{g} / \mathrm{cm})$} & \multicolumn{2}{|c|}{$\begin{array}{l}\text { Static and dynamic } \\
\text { bulk density }\left(\mathrm{g} / \mathrm{cm}^{3}\right)\end{array}$} & \multirow[t]{2}{*}{ Angle of repose $\theta\left(^{\circ}\right)$} \\
\hline & & & $\rho_{\mathrm{b} 1}$ & $\rho \mathrm{b} 2$ & \\
\hline \multirow{3}{*}{ Glass beads } & 0.180 & 79.6 & 1.488 & 1.524 & 20 \\
\hline & 0.505 & 84.0 & 1.578 & 1.547 & 26 \\
\hline & 1.015 & 83.6 & 1.562 & 1.545 & 20 \\
\hline \multirow{3}{*}{ Styrol resin } & 0.359 & 37.9 & 0.682 & 0.706 & 20 \\
\hline & 0.505 & 37.5 & 0.724 & 0.740 & 21 \\
\hline & 2.605 & $\ldots \ldots *$ & 0.673 & 0.689 & 31 \\
\hline \multirow{4}{*}{ Silica sand } & 0.180 & 71.4 & 1.288 & 1.382 & 36 \\
\hline & 0.254 & 72.5 & 1.329 & 1.423 & 35 \\
\hline & 0.505 & 77.0 & 1.328 & 1.381 & 35 \\
\hline & 0.715 & 75.6 & 1.511 & 1.488 & 40 \\
\hline \multirow{3}{*}{ Carborundum } & 0.180 & 83.9 & 1.819 & 1.861 & 34 \\
\hline & 0.505 & 87.8 & 1.705 & 1.677 & 37 \\
\hline & 1.435 & 81.3 & 1.682 & 1.668 & 42 \\
\hline \multirow{3}{*}{ Silica gel } & 0.505 & 48.8 & 0.892 & 0.925 & 34 \\
\hline & 0.715 & 42.9 & 0.957 & 0.933 & 33 \\
\hline & 1.015 & 45.6 & 0.943 & 0.953 & 37 \\
\hline
\end{tabular}

* The value of $\mathrm{K}$ could not be obtained because $\mathrm{d}$ is so large and the measurable data under the same condition were insufficient.

\section{4. 実験結果 - 考察}

\section{1 貫入深さ $\boldsymbol{x}(\mathbf{m m})$ と錘 $\boldsymbol{M}(\mathbf{g})$ との関係}

図-2（a), (b) は $x$ と M の関係図（側面にエメリー ペーパ AA 60 を貼付 (記号 $\triangle$ ), 底面と側面に貼付 (記

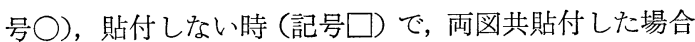
は $M$ の増加と共に $x$ も増加するが，貼付方法による差 はほとんどみられない。粒径が小さいとき貼付しない場 合の方が同一の $M$ に対して棒が深く貫入するのは，錘 を棒上に落下したとき，粒子間の摩擦が大粒子に比較し
て少ないが，貼付すると粗面になり，この粗面による粒 子の抵抗が大きいため，特に $M$ が大きくなるにつれて $x$ の值に大きな差を生じたものと考えられる。

$4.2 \boldsymbol{K}(\mathrm{g} / \mathrm{cm})$ と静かさ密度 $\boldsymbol{\rho}_{b 1}\left(\mathrm{~g} / \mathrm{cm}^{3}\right)$ ・動かさ密 度 $\boldsymbol{\rho}_{b 2}\left(\mathbf{g} / \mathbf{c m}^{3}\right)$ および安息角 $\boldsymbol{\theta}\left({ }^{\circ}\right)$ との関係

流出実験の総括表（表-2）からプロットした結果を 図-3（a ，，(b) に示す。 $K$ は単位流下距離むたりの重 量を表わし，図-3（a）からわかるように，粉体の種 類・粒径にほぼ無関係に, かさ密度が増加するほど $K$ も比例的に増加している。このことはかさ密度が増加す 

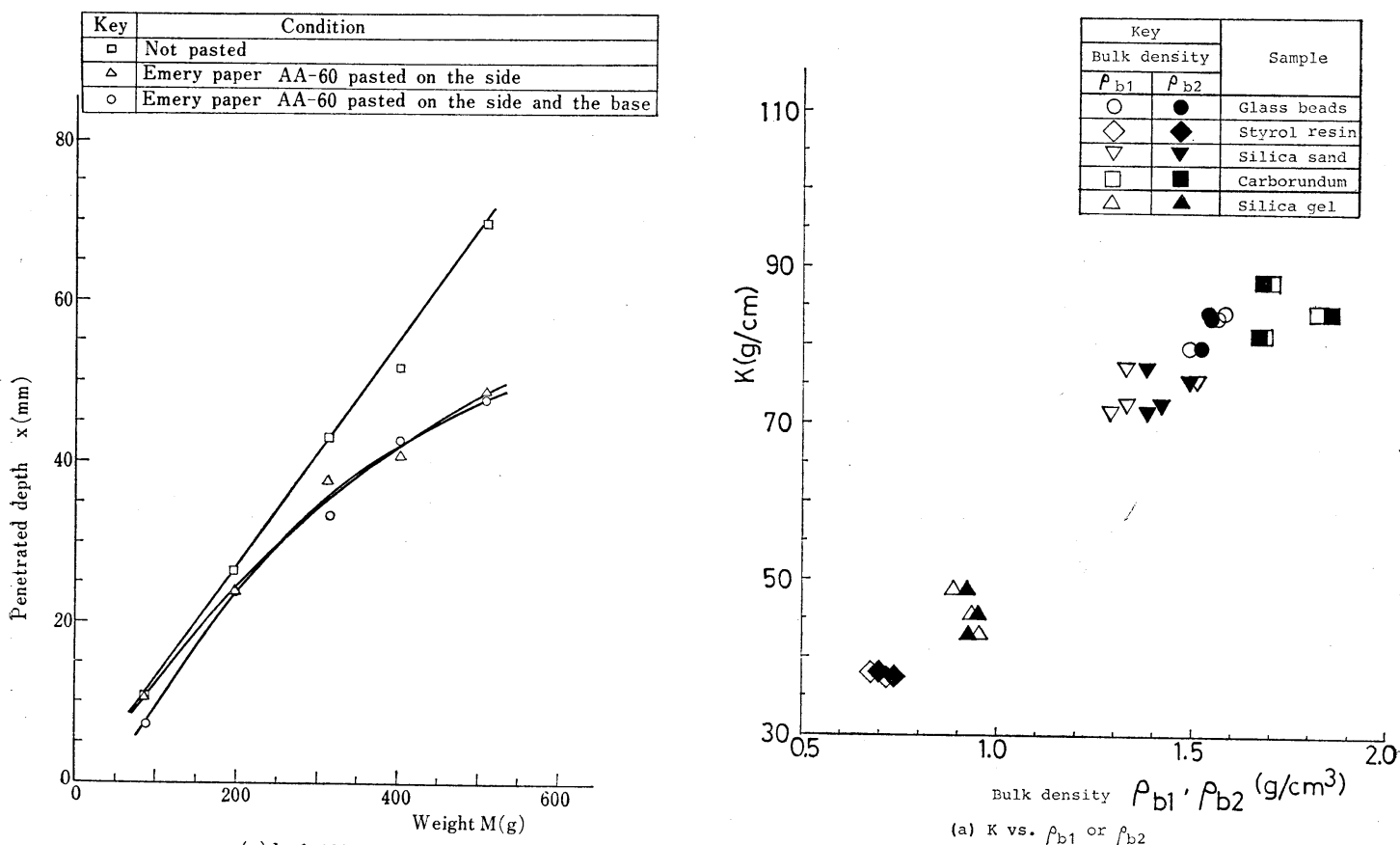

(a) $\mathrm{d}=0.180 \mathrm{~mm}$

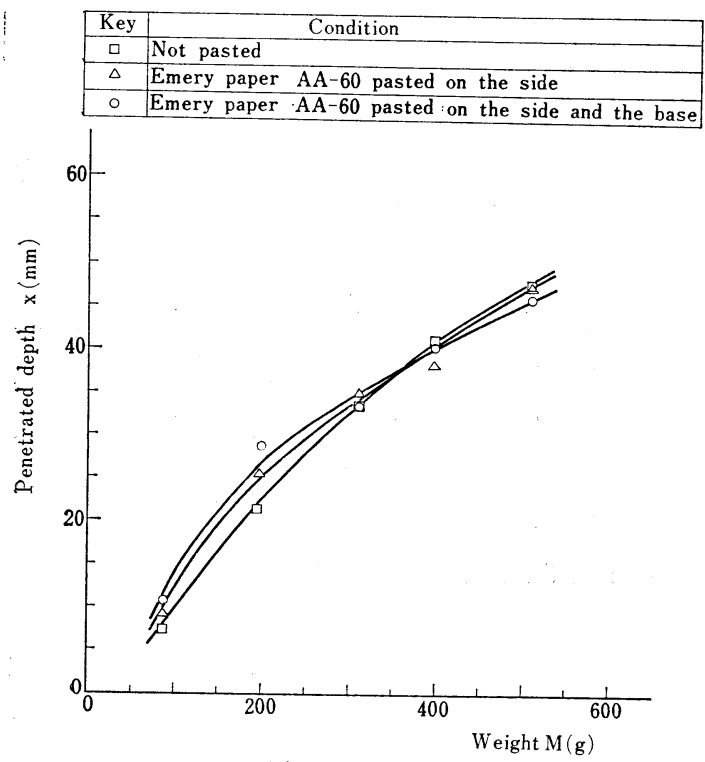

(b) $\mathrm{d}=2.030 \mathrm{~mm}$

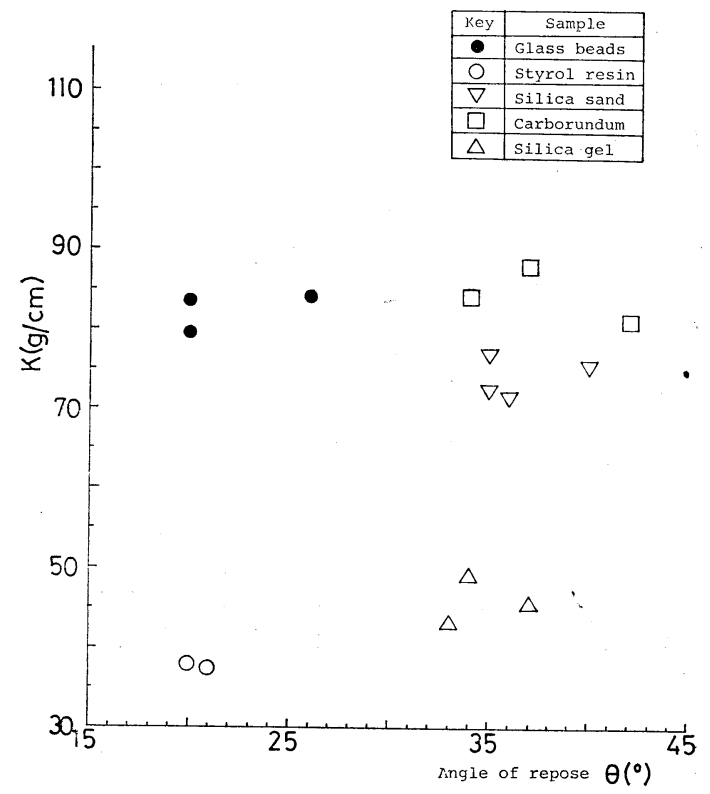

(b) K vs. $\theta$

Fig. 2. Relationship between $x$ and $M$ (Glass beads)

Fig. 3. Relationship between $K$ and $\rho_{b_{1}}, \rho_{b 2}$ or $\theta$

るほど流動性がよいことを表わす。他方，図-3（b）の $K$ と $\theta$ との関係は, 各粉体ごとに明確には断定できない が，表面の滑らかな球形粒子であるガラスビーズやスチ ロールは $\theta$ が小さいが，ガラスビーズの比重がスチロー

ルの 2 倍以上に大きいため, $K$ の值も大きい。他の 3 種 類の粉体は粒子表面の形状が滑らかでないため,すべり が悪く, 粒子と粒子との反発が少なく, 堆積しやすい性 質を有するので $\theta$ が大きくなる。 


\section{5. 結}

言

上述の実験結果を要約すると次のようになる。

（1）貫入棒の粉体層への貫入特性は，棒に粒度の大 きいェメリーペーパを貼付する方法と貼付しない場合と を比較した結果, 粒径が大きいとき両者間に顕著な差は 認められないが，粒径が小さいとき貼付しない方が深く 貫入する。

（2）流出比 $K$ は粉体の種類および粒径に 無 関 係 に, かさ密度が増加するに従って直線的に増加するが, $K$ と安息角との間には明確な関係が得られなかった。
謝 辞

本研究に打いて適切な御助言をいただいた川北技研会 長川北公夫博士に感謝する。

\section{参考文献}

1）寺下.大村 - 宮南 : 材料, 第 31 巻, 第 348 号, (1982), p. 883

2）高木・杉田：粉体工学会誌，第 16 巻，第 9 号, (1979), p. 528

3）山城・湯浅 : 第 27 回材料研究連合講演会前刷集 (1983), p. 184

4）湯浅・山城：第 27 回材料研究連合講演会前刷集 (1983), p. 182

\title{
Study on the Fundamental Properties of Powder Solids (V)
}

\section{Penetration of a Bar into Powder Solids Layer and Relationship between}

Discharge Ratio and Bulk Density or Angle of Repose

\author{
Yasunobu YuASA* and Mitsuo Yamashiro* \\ * Department of Planning Technology, Ashikaga Institute of Technology
}

\begin{abstract}
In practice, powder solids dealt with industrially have grain sizes and the shapes of particles are irregular. In the previous report, the authors have carried out the experiments related to tapping and abulk density by using two kinds of industrial powders (starch and talc) and its mixed powders and those correlations have been described.

In this study, the experiment of the penetration of a bar into powder solids layer and that of the flow-out of the powder solids through an orifice on the bottom of a vessel were carried out. The following facts were made clear:

(1) In the former, the smaller the particle diameter is, a penetrating bar penetrates deeper when an emery-paper is not pasted on it.

(2) In the latter, the discharge ratio increases linearly with an increase of bulk density, but the relationship for angle of repose can not be shown clearly.
\end{abstract}

\section{協賛関係}

第 16 回日本色彩学会全国大会付設展示会

主 催 日本色彩学会

協 替 色材協会, 他
日 時 昭和 60 年 5 月 18 日 (土) 19 日(日)

場 所 大阪電気通信大学 (大阪府寝屋川市初町 18-8)

内 容 色彩関連機器及び資料等の展示 